\title{
PENGARUH TALENT MANAGEMENT TERHADAP EMPLOYEE RETENTION DENGAN EMPLOYEE ENGAGEMENT SEBAGAI VARIABEL MEDIASI
}

\author{
Dian Putri Dewi Ratnawati ${ }^{1}$ \\ Made Subudi ${ }^{2}$ \\ ${ }^{1,2}$ Fakultas Ekonomi dan Bisnis Universitas Udayana, Bali, Indonesia \\ e-mail: hoooku@yahoo.com
}

\begin{abstract}
ABSTRAK
Employee retention merupakan upaya untuk mendorong karyawan berbakat agar memiliki loyalitas tinggi. Tingkat employee retention yang tinggi mampu dicapai jika perusahaan memperhatikan faktor talent management dan employee engagement. Tujuan dari penelitian ini untuk menguji pengaruh talent management terhadap employee retention dengan employee engagement sebagai variabel mediasi pada karyawan Sardine Restaurant Seminyak Bali. Penelitian menggunakan metode sensus dalam menentukan sampel sebanyak 60 responden, melalui teknik analisis jalur. Berdasarkan hasil analisis dapat diketahui bahwa talent management memiliki pengaruh positif dan signifikan terhadap employee engagement. Talent management memiliki pengaruh positif dan signifikan terhadap employee retention. Employee engagement memiliki pengaruh positif dan signifikan terhadap employee retention. Employee engagement mampu memberikan pengaruh positif dalam memediasi hubungan talent management terhadap employee retention pada karyawan Sardine Restaurant Seminyak Bali.
\end{abstract}

Kata Kunci: talent management, employee engagement, employee retention

\begin{abstract}
Employee retention is an effort to encourage talented employees to have high loyalty. High employee retention rates can be achieved if the company takes into account the factors of talent management and employee engagement. The purpose of this study was to examine the effect of talent management on employee retention with employee engagement as a mediation variable at the employees of Sardine Restaurant Seminyak Bali. The study used the census method in determining the sample of 60 respondents, through path analysis technique. Based on the analysis results can be seen that talent management has a positive and significant influence on employee engagement. Talent management has a positive and significant influence on employee retention. Employee engagement has a positive and significant impact on employee retention. Employee engagement is able to give positive influence in mediating talent management relationship to employee retention on Sardine Restaurant Seminyak Bali employee.
\end{abstract}

Keywords: talent management, employee engagement, employee retention 


\section{PENDAHULUAN}

Persaingan usaha pada era milenium saat ini ditandai dengan perubahan iklim bisnis yang cepat serta tantangan usaha yang kritis dan kompetitif. Inten (2016) menyatakan bahwa, bisnis dipengaruhi oleh perkembangan jaman yang semakin maju terutama bisnis kuliner. Menurut Adi (2012), strategi dan perubahan dari sisi internal perusahaan diperlukan agar mampu menjadi pemenang dalam menghadapi persaingan eksternal yang semakin ketat. Para pelaku bisnis perlu memaksimalkan kinerja perusahaannya agar mampu bersaing dan dapat bertahan dalam persaingan bisnis.

Menurut Kossivi et al. (2016) karyawan memiliki peran yang cukup penting dalam kinerja suatu perusahaan, karyawan dikatakan sebagai penentu maju mundurnya suatu perusahaan. Menarik sebanyak mungkin karyawan-karyawan berbakat serta mempertahankan mereka di tempat kerja untuk jangka waktu panjang menjadi kunci memenangkan kompetisi usaha. Wijayanti (2015) menyatakan bahwa, faktor employee retention dikatakan sebagai faktor yang mempengaruhi keberhasilan dalam peningkatan produktivitas dan peningkatan profitabilitas suatu perusahaan. Menurut Kyndt (2009), employee retention diperlukan sebagai fungsi dan daya saing perusahaan. Mempertahankan karyawan bertalenta dan terampil penting dalam suatu persaingan, pengetahuan dan keterampilan karyawan dibutuhkan bagi perusahaan ketika bersaing terhadap kompetitor, perusahaan berevolusi melalui karyawan mereka dan belajar untuk pengembangan karyawan secara berkelanjutan. 
Permasalahan internal yang terjadi pada Sardine Restaurant Seminyak Bali yaitu pada 5 tahun terakhir mengalami perputaran karyawan yang cukup signifikan, banyak karyawan yang keluar masuk karena kurang efektifnya pengelolaan talenta karyawan. Perusahaan juga dinilai kurang mampu mencocokkan karyawan untuk ditempatkan pada posisi yang tepat sesuai dengan skill yang mereka miliki, disamping itu, karyawan merasa kurang memiliki kesempatan untuk mengembangkan karir di perusahaan, sehingga karyawan cenderung memiliki loyalitas yang rendah di tempat mereka bekerja, terutama para karyawan yang memiliki kompetensi dan keterampilan tinggi tidak sedikit yang memilih untuk mengundurkan diri.

Turnover karyawan Sardine Restaurant Seminyak Bali serta jumlah karyawan yang keluar masuk cukup signifikan. Tingkat turnover yang paling tinggi dirasakan pada tahun 2014 sebesar 15,09\%. Tingkat turnover yang paling rendah terjadi pada tahun 2012 sebesar 9,61\%. Turnover karyawan ini terjadi secara keseluruhan di perusahaan serta tidak dapat dipungkiri akan berdampak pada setiap bagian di perusahaan.

Menurut Mathis dan Jackson (2009), Tingkat perputaran karyawan (turnover intention) dimana karyawan meninggalkan perusahaan dan harus digantikan dengan karyawan baru ditentukan oleh employee retention. Intensi turnover karyawan dapat ditekan melalui proses recruitment yang lebih efektif dan pemilihan kandidat yang sesuai dengan talent yang dibutuhkan perusahaan dalam 5 tahun terakhir. Latha et al. (2015) menyatakan bahwa, employee retention yang tinggi dibutuhkan bagi semua jenis organisasi guna meminimalkan turnover 
dan mendukung performance bisnis dalam organisasi. Menurut Sumarni (2011), rendahnya kinerja disebabkan buruknya employee retention pada perusahaan tersebut.

Ali et al. (2014) menyatakan bahwa, kinerja organisasi dalam mencapai suatu tujuan dipengaruhi pada tinggi rendahnya employee retention. Menurut Mathis dan Jackson (2006: 128), retensi karyawan didefinisikan sebagai kemampuan dan upaya manajemen organisasi untuk mendorong karyawan berbakat (talented employee) agar memiliki rasa loyalitas tinggi. Hasrat yang ada pada diri individu untuk ingin tetap tinggal dalam suatu perusahaan untuk periode yang lama ditentukan oleh seberapa besar retensi terhadap karyawan. Menurut Tangthong et al. (2014), Kualitas kerja memburuk ketika tidak didukung perhatian perusahaan, hal itu akan berdampak kepada penurunan komitmen dalam organisasi dan berkurangnya totalitas dalam bekerja serta memberikan pengaruh yang besar terhadap pencapaian tujuan organisasi.

Efektifnya employee retention dipengaruhi oleh beberapa faktor yaitu talent management, employee recruitment, dan employee engagement (Julia et al., 2008). Menurut Hughes (2008), jika talent management efektif maka employee retention juga akan berjalan dengan efektif. Talent management merupakan suatu bagian integral untuk melibatkan karyawan di dalam organisasi. Setiap karyawan menginginkan posisi bekerja sesuai dengan potensi mereka. Karyawan akan merasa antusiasme dalam bekerja ketika perusahaan mampu memposisikan mereka pada pekerjaan dan bidang sesuai dengan bakat dan kemampuan. 
Menurut Bhatnagar (dalam Yona et al. 2015), employee retention (retensi karyawan) akan menurun ketika tidak diimbangi dengan pelaksanaan manajemen bakat (talent management) dalam perusahaan yang terkelola dengan baik. (Jacksonville and Scholar, 1990) menyatakan bahwa, talent management didefinisikan sebagai perencanaan dan analisis tenaga kerja serta proses pengelolaan karyawan melalui perekrutan, pelatihan dan pengembangan talenta yang memberikan kontribusi dalam kesuksesan perusahaan. Talent management mengacu pada proses yang sistematis dan dinamis dalam menemukan, mengembangkan dan mempertahankan bakat. Apabila bakat karyawan mampu dikelola dengan baik maka karyawan pun memiliki semangat dan berkurangnya rasa bosan dalam bekerja..

Employee retention yang tinggi ditentukan oleh keberhasilan organisasi dalam mengatur bakat karyawan mereka sehingga membantu organisasi dalam mengurangi tingginya turnover karyawan karena ketidakcocokan dengan pekerjaan (Mohsen, 2007). Talent management mendorong tingginya employee retention melalui upaya pengelolaan arus sumber daya manusia pada seluruh bagian organisasi (Lewis and Heckman, 2006). (Holland et al., 2007) menyatakan bahwa, talent management merupakan proses dalam pengelolaan SDM dan penyaluran bakat karyawan. Penyaluran bakat karyawan mendorong employee retention organisasi, sehingga organisasi mampu memiliki daya saing untuk menghadapi lingkungan yang kompetitif. 
Dian Putri Dewi Ratnawati dan Made Subudi, Pengaruh Talent....

Julia et al. (2008) menyatakan bahwa, talent management merupakan konsep multi-faceted yang berfokus kepada human resource planning, meliputi employee recruitment dan employee retention. Program talent management digunakan pada perusahaan dan sebagian besar kegiatan program talent management berkaitan dengan aktivitas SDM meliputi recruitment, selection, development, evaluation, retention dan succession planning (Pimapunsri, 2013). Glen (2006) menyatakan bahwa, employee engagement merupakan faktor yang memberikan pengaruh pada retensi karyawan (employee retention) dalam perusahaan. Organisasi mampu memiliki profitabilitas yang tinggi ketika didukung oleh pelaksanaan manajemen bakat (talent management) yang efektif dan keterikatan karyawan (employee engagement).

Menurut Schaufeli (2002), employee engagement didefinisikan sebagai keadaan motivasional yang positif yang mengandung karakteristik persistensi, antusiasme, dan totalitas terhadap pekerjaan. Keterkaitan positif antara talent management dengan employee retention didalam perusahaan dipengaruhi oleh peranan employee engagement (Alias et al. 2014). Employee engagement mendorong efektifitas talent management pada organisasi dan memberikan peningkatan terhadap employee retention (Tiwari \& Shrivastava, 2013). Karyawan dalam suatu perusahaan akan terikat serta memiliki ambisi untuk berkontribusi demi tujuan organisasi ketika mereka merasa diapresiasikan oleh pimpinan mereka (Davies et al. 2010).

Karyawan yang merasa dianggap bernilai, dihargai, dan diakui keberadaannya akan lebih termotivasi dan meningkatkan diri dalam pekerjaan, 
karyawan akan engage jika perusahaan dirasa mampu memberikan mereka kenyamanan dalam bekerja dibandingkan dengan karyawan yang tidak merasa diapresiasikan oleh perusahaan (Aljunabi, 2014). Dhanalaksmi et al. (2014) mengemukakan bahwa, engagement karyawan yang meningkat akan membawa pengaruh yang besar pada produktivitas dan retensi karyawan (employee retention) yang meningkat pula. Albrecht (2010) mengemukakan bahwa, employee engagement digambarkan sebagai hasrat para anggota organisasi terhadap pekerjaan mereka dalam suatu perusahaan. Peran employee engagement juga membantu karyawan mengekpresikan diri mereka secara kognitif dan emosional dalam bekerja.

Sardine Restaurant Seminyak Bali merupakan salah satu usaha yang bergerak di bidang kuliner yang berlokasi di daerah Seminyak. Sardine Restaurant Seminyak Bali mengangkat menu european gluten-free sebagai menu sajian utama. Restaurant ini menerapkan konsep ricefields view dengan perpaduan atmosphere rustic dan budaya lokal Indonesia sebagai daya tarik kepada konsumen. Sardine Restaurant Seminyak Bali memberikan berbagai pilihan menu eropa yang bebas gluten dikombinasi dengan menu vegetarian, seperti Yellowfin tuna carpaccio, Blackened albacore tuna, Mediterranean green salad with calamari, Jamon serrano, Vietnamese grilled chicken dan Tasmanian salmon tartare. Sardine Restaurant Seminyak Bali juga memiliki beberapa main course menu yaitu Grilled sardine, Grilled hamachi, Sautéed wild snapper, Sauteed kingfish serta Pan roasted mahi-mahi. 
Dian Putri Dewi Ratnawati dan Made Subudi, Pengaruh Talent....

Dalam menunjang kegiatan operasional, Sardine Restaurant Seminyak Bali membutuhkan sumber daya manusia (SDM) yang berkompeten di masing-masing bagian pekerjaan. Hasil observasi awal yang dilakukan terhadap beberapa karyawan Sardine Restaurant Seminyak Bali, yaitu dua orang karyawan di bagian waiter, satu orang karyawan di bagian food and beverage service, empat orang karyawan di bagian sale and marketing dan dua orang karyawan di bagian purchasing. Melalui wawancara awal yang dilakukan, ditemukan beberapa permasalahan internal pada Sardine Restaurant Seminyak Bali yang secara garis besar masalah internal tersebut mengenai kurangnya pengelolaan organisasi pada talent management dan karyawan kurang memiliki kesempatan dalam mengembangkan karir di perusahaan sehingga karyawan merasa kurang memiliki rasa keterikatan terhadap organisasi tempat mereka bekerja, karyawan merasa kurang mendapatkan perhatian pada penempatan kerja sesuai dengan talenta yang dimiliki di perusahaan. Banyak karyawan merasa bahwa perusahaan kurang sesuai melakukan penempatan karyawan sehingga semangat kerja, loyalitas, sikap dan disiplin karyawan menurun.

Penelitian ini secara empiris mencoba untuk meneliti hubungan antara talent management, employee engagement dan employee retention. Penelitian ini merupakan replikasi dari penelitian sebelumnya yang dilakukan oleh Nurul et al. (2014) yang secara empiris meneliti mengenai hubungan talent management practices, employee engagement dan employee retention. Berdasarkan hal tersebut perusahaan perlu berfokus pada talent management untuk melibatkan karyawan 
yang dapat berpengaruh pada employee retention. Sehingga karyawan dapat memberikan kontribusi yang maksimal kepada perusahaan.

Employee engagement sebagai mediasi antara talent management terhadap employee retention pada karyawan di Sardine Restaurant Seminyak Bali memiliki kontribusi dalam hubungan secara tidak langsung antara talent management terhadap employee retention sehingga employee engagement membantu mempertahankan karyawan-karyawan perusahaan yang berkompeten dengan membuat karyawan merasa memiliki perusahaan tempat mereka bekerja dan memiliki rasa keterikatan dalam jangka panjang terhadap organisasi.

Hasil penelitian Nurul et al. (2014) menunjukkan bahwa, manajemen bakat memiliki korelasi positif dengan employee engagement. Hasil analisis regresi hirarkis mengindikasikan hubungan positif antara praktek talent management (pengembangan potensi karyawan) dan employee engagement. Hasil penelitian Ali et al. (2014) menunjukkan bahwa, praktek talent management menjadi bagian penting untuk organisasi modern karena munculnya para pelaku ekonomi modern, generasi baru menjadi calon karyawan yang kompetitif dan kebutuhan bagi perusahaan untuk menjadi lebih strategis dan kompetitif, yang berarti menggunakan cara baru dalam mengelola sumber daya dan modal manusia. Hasil penelitian Irmawaty \& Mailani (2016) menunjukkan bahwa, ada hubungan yang signifikan antara talent management dengan employee engagement.

Mohamed (2014) membuktikan bahwa, talent management mempunyai korelasi positif dan berpengaruh signifikan terhadap employee engagement. Thakur (2015) membuktikan dalam penelitiannya bahwa, talent management 
Dian Putri Dewi Ratnawati dan Made Subudi, Pengaruh Talent....

memiliki impact positive dan signifikansi dengan employee engagement. Berdasarkan uraian penelitian diatas, maka dikemukakan hipotesis sebagai berikut:

$\mathrm{H}_{1} \quad$ : Talent management berpengaruh signifikan dan positif terhadap employee engagement

Davis et al. (2007) menyatakan bahwa, langkah yang paling penting dari talent management adalah retensi karyawan berbakat dalam organisasi. Hal ini karena karyawan berbakat diyakini sebagai suatu investasi utama organisasi dan memberikan alasan mengapa perusahaan perlu mempertahankan mereka dalam organisasi. Oladapo (2014) membuktikan bahwa, terdapat hubungan positif antara variabel talent management dengan employee retention. Kataike (2013) dalam penelitiannya membuktikan bahwa, terdapat hubungan positif serta signifikan antara talent management dengan employee retention. Phelister (2016) membuktikan bahwa, talent management mempunyai pengaruh signifikan terhadap employee retention. Berdasarkan uraian penelitian diatas, maka dikemukakan hipotesis sebagai berikut:

$\mathrm{H}_{2} \quad$ : Talent management berpengaruh signifikan dan positif terhadap employee retention

Penelitian Yogendra (2015) membuktikan bahwa, employee engagement ditemukan memiliki signifikansi yang kuat dan hubungan positif terhadap employee retention. Dash (2013) dalam penelitiannya membuktikan bahwa, employee engagement memiliki pengaruh positif pada employee retention. Penelitian Tangthong (2014) menemukan bahwa, employee engagement memiliki 
hubungan signifikan dan korelasi positif dengan employee retention. Hal yang sama dinyatakan oleh Oladapo (2014), terciptanya hubungan positif antara variabel employee engagement dengan employee retention. Berdasarkan uraian penelitian diatas, maka dikemukakan hipotesis sebagai berikut:

$\mathrm{H}_{3} \quad$ : Employee engagement berpengaruh signifikan terhadap employee retention.

Ali \& Hamid (2014) menyatakan bahwa, employee engagement sebagai variabel mediasi mampu menciptakan hubungan positif antara talent management dengan employee retention. Bidayatul (2015) dalam penelitiannya membuktikan bahwa, employee engagement merupakan variabel yang memediasi hubungan antara talent management terhadap employee retention. Dipertegas oleh penelitian Stefanus \& Echy (2014), employee engagement mampu memediasi pengaruh positif talent management terhadap employee retention. Theresha \& Tinjung (2015) membuktikan bahwa, employee engagement mampu memediasi variabel talent management dengan employee retention. Berdasarkan uraian penelitian diatas, maka dikemukakan hipotesis sebagai berikut:

$\mathrm{H}_{4} \quad$ : Employee engagement memediasi pngaruh talent management terhadap employee retention.

\section{METODE PENELITIAN}

Penelitian ini adalah penelitian asosiatif yang bertujuan untuk mengetahui hubungan antar dua variabel atau lebih (Sugiyono, 2013:11). Penggunaan metode ini untuk menganalisis pengaruh talent management terhadap employee retention melalui mediasi employee engagement pada karyawan Sardine Restaurant Seminyak Bali. 
Lokasi penelitian dilakukan di Sardine Restaurant Seminyak Bali yang beralamat di Jalan Petitenget No. 21 Seminyak Kerobokan. Peneliti memilih lokasi ini sebagai tempat penelitian karena ditemukannya masalah internal perusahaan yang terkait dengan masalah rendahnya employee retention yang dipengaruhi oleh beberapa faktor yaitu lemahnya perhatian dari organisasi dalam pengelolaan manajemen bakat (talent management) serta kurangnya rasa keterikatan karyawan (employee engagement) pada organisasi. Sedangkan objek penelitiannya adalah talent management, employee engagement, dan employee retention pada karyawan Sardine Restaurant Seminyak Bali.

Variabel terikat dalam penelitian ini adalah employee retention (Y) yang diukur dengan menggunakan lima indikator yaitu penghargaan, komponen organisasional, peluang karier, hubungan kerja, rancangan dan tugas pekerjaan. Variabel bebas dalam penelitian ini adalah talent management $(\mathrm{X})$ yang diukur dengan menggunakan enam indikator yaitu perspektif kompetitif, perspektif proses, perspektif perencanaan SDM, perspektif pengembangan, perspektif budaya, dan perspektif manajemen perubahan. Sedangkan variabel mediasi dalam penelitian ini adalah employee engagement $(\mathrm{M})$ yang diukur dengan menggunakan enam indikator yaitu kesiapan, kerelaan, dan kebanggaan.

Jenis data yang digunakan dalam penelitian ini adalah data kuantitatif berupa jumlah karyawan dan data yang langsung didapat dari karyawan dengan cara penyebaran kuesioner. Data kualitatif digunakan dalam penelitian ini adalah sejarah singkat organisasi, struktur dan uraian tugas. Sedangkan sumber data yang digunakan dalam penelitian ini adalah sumber primer berupa data yang didapat 
dari kuesioner yang disebarkan dan observasi secara langsung. Sumber sekunder berupa keberadaan perusahaan, sejarah perusahaan, jumlah karyawan dan struktur organisasi.

Populasi dalam penelitian ini adalah karyawan Sardine Restaurant Seminyak Bali tahun 2017, berjumlah 60 orang termasuk 1 orang operational manager dan 1 orang HRD manager. Pengumpulan sampel menggunakan sampel jenuh. Sampel jenuh adalah teknik penentuan sampel apabila semua anggota populasi digunakan sebagai sampel, hal ini sering dilakukan bila jumlah populasi relatif kecil,berkisar 40 orang (Sugiyono, 2013:68).

Metode pengumpulan data yang digunakan dalam penelitian ini adalah metode wawancara dan kuesioner. Wawancara dilakukan saat peneliti ingin melakukan studi untuk menemukan permasalahan yang harus diteliti, dan apabila peneliti ingin mengetahui hal-hal dari responden yang mendalam dimana jumlah respondennya sedikit atau kecil. Kuesioner dilakukan dengan cara memberi seperangkat pertanyaan atau pernyataan tertulis kepada responden untuk dijawabnya.

Penelitian ini menggukanan teknik analisis jalur (path analysis). Pengaruh talent management $(\mathrm{X})$ terhadap employee retention $(\mathrm{Y})$ ditunjukkan oleh koefisien jalur $\mathrm{b}$, pengaruh langsung talent management $(\mathrm{X})$ terhadap employee engagement (M) diperlihatkan oleh koefisien jalur a, dan pengaruh employee retention (Y) terhadap employee engagement $(\mathrm{M})$ diperlihatkan oleh koefisien jalur c. Pengaruh tidak langsung talent management $(\mathrm{X})$ terhadap employee engagement $(\mathrm{M})$ diperoleh dengan mengalikan a dan $\mathrm{b}$. 


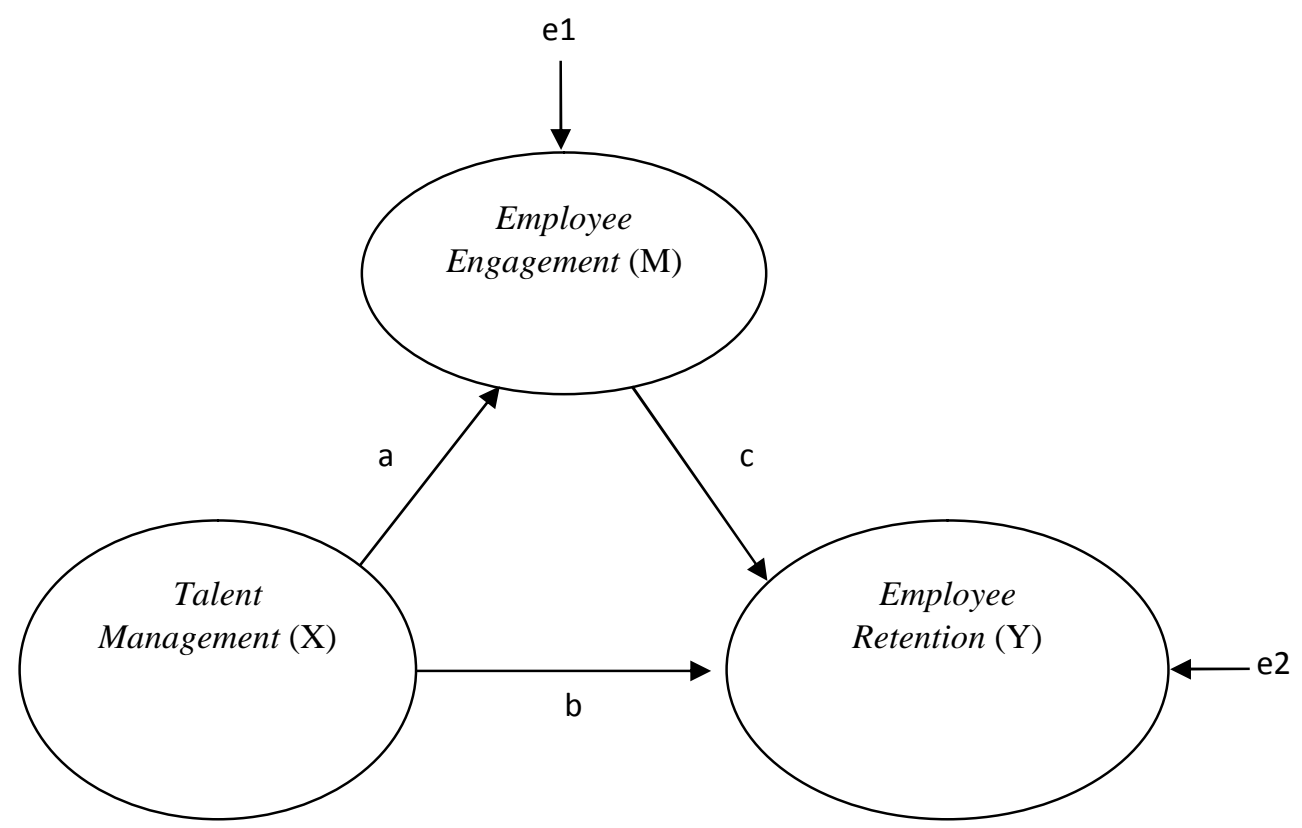

Gambar 1. Diagram Jalur Penelitian

Keterangan:

$\mathrm{X} \quad=$ variabel eksogen talent management

$\mathrm{M}=$ variabel mediasi employee engagement

$\mathrm{Y} \quad=$ variabel endogen employee retention

$\mathrm{a}, \mathrm{b}, \mathrm{c}=$ koefisien regresi untuk masing-masing variabel $\mathrm{X}$

$\mathrm{e}_{1}, \mathrm{e}_{2}=$ nilai kekeliruan taksiran standar

Model persamaan struktural diatas juga dapat dinyatakan dalam bentuk

persamaan atau diagram jalur sehingga disebut juga dengan sistem persamaan simultan atau model struktural sebagai berikut :

$$
\begin{aligned}
& \mathrm{M}=\mathrm{aX}+\mathrm{e} 1 \ldots \ldots \\
& \mathrm{Y}=\mathrm{aX}+\mathrm{bM}+\mathrm{e} 2
\end{aligned}
$$

Keterangan:

$\mathrm{Y} \quad=$ kinerja

a $\quad=$ koefisien jalur dari talent management

$\mathrm{b} \quad=$ koefisien jalur dari employee engagement

$\mathrm{X}=$ talent management

$\mathrm{M}=$ employee engagement

$\mathrm{e}_{1} \quad=$ nilai kekeliruan taksiran standar

$\mathrm{e}_{2}=$ nilai kekeliruan taksiran standar 


\section{Uji Mediasi (Uji Sobel)}

Untuk menguji signifikansi peran mediasi variabel employee engagement digunakan rumus Sobel. Berdasarkan diagram jalur pengaruh tidak langsung, maka dapat dihitung standar error koefisien a dan b ditulis dengan $S_{a}$ dan $S_{b}$, besarnya standar error tidak langsung (indirect effect) $\mathrm{S}_{\mathrm{ab}}$ dihitung dengan rumus berikut ini:

$$
\mathrm{S}_{\mathrm{ab}}=\sqrt{b^{2} S_{a}^{2}+a^{2} S_{b}^{2}+S_{a}^{2} S_{b}^{2}}
$$

Keterangan :

$\mathrm{S}_{\mathrm{ab}}=$ besarnya standar error tidak langsung

$\mathrm{S}_{\mathrm{a}} \quad=$ standar error koefisien a

$\mathrm{Sb}=$ standar error koefisien $\mathrm{b}$

a $\quad$ jalur $\mathrm{X}$ terhadap $\mathrm{M}$

$\mathrm{b} \quad=$ jalur M terhadap $\mathrm{Y}$

Apabila hasil nilai perhitungan Z > 1,96 (tingkat kepercayaan 95 persen), maka variabel intervening dianggap secara signifikan memediasi hubungan antara variabel eksogen dan variabel endogen.

\section{HASIL DAN PEMBAHASAN}

\section{Karakteristik Responden}

Dari hasil penelitian yang dilakukan terhadap karyawan di Sardine Restaurant Seminyak Bali, dapat diketahui gambaran tentang karakteristik responden yang meliputi tiga aspek yaitu umur, jenis kelamin, pendidikan terakhir dan lama bekerja. 
Tabel 1.

Karakteristik Responden

\begin{tabular}{ccccc}
\hline No & Variabel & Klasifikasi & Jumlah & Persentase (\%) \\
\hline 1 & Umur & $17-25$ & 23 & 39,6 \\
& & $26-35$ & 14 & 24,1 \\
& $36-45$ & 13 & 22,4 \\
& & $46-55$ & 8 & 13,8 \\
\hline & & $\mathbf{5 8}$ & $\mathbf{1 0 0}$ \\
\hline 2 & Jumlah & & 23 & 39,6 \\
& Jenis Kelamin & Laki-laki & 35 & 60,4 \\
\hline \multirow{2}{*}{3} & Jumlah & Perempuan & $\mathbf{5 8}$ & $\mathbf{1 0 0}$ \\
& Pendidikan & SLTP & 5 & 8,6 \\
& & SLTA & 14 & 24,2 \\
& & Diploma 3 (D3) & 18 & 31,0 \\
& & Sarjana (S1) & 21 & 36,2 \\
\hline \multirow{2}{*}{4} & & $\mathbf{5 8}$ & $\mathbf{1 0 0}$ \\
& Jumlah & 1 Tahun & 5 & 8,6 \\
& Lama Bekerja & 1- 2 Tahun & 11 & 18,9 \\
& & 2 - 4 Tahun & 27 & 46,5 \\
& & 4 Tahun & 15 & 25,8 \\
\hline & & $\mathbf{5 8}$ & $\mathbf{1 0 0}$ \\
\hline
\end{tabular}

Sumber: Data primer diolah, 2017

Tabel 1 menunjukkan bahwa sebagian besar responden berumur 17-25 tahun dengan persentase yaitu 39,6 persen. Persentase terkecil yaitu 13,8 persen dengan jumlah responden sebanyak 8 orang yang berumur $46-55$ tahun. Hal ini berarti bahwa, karyawan Sardine Restaurant Seminyak Bali rata-rata berumur 1725 tahun. Dalam hal ini Sardine Restaurant Seminyak Bali lebih memilih usia produktif untuk menunjang pelayanan yang efektif dan efesien kepada pengunjung, khususnya wisatawan mancanegara yang lebih mengutamakan pelayanan yang cepat dan terampil. Berdasarkan jenis kelamin menunjukkan bahwa jumlah responden laki-laki sebanyak 23 orang dengan persentase laki-laki sebesar 39,6 persen sedangkan perempuan sebesar 60,4 persen. Hal ini berarti sebagian besar karyawan Sardine Restaurant Seminyak Bali didominasi oleh karyawan perempuan. Sardine Restaurant Seminyak Bali sebagai usaha yang bergerak dibidang kuliner, dalam hal ini restaurant lebih mengutamakan 
pelayanan yang menarik sehingga lebih mengutamakan karyawan perempuan dalam menjalankan operasionalnya.

Berdasarkan tingkat pendidikan menunjukkan bahwa sebagian besar responden memiliki tingkat pendidikan Sarjana (S1) yaitu sebesar 36,2 persen, sedangkan responden dengan persentase terkecil berpendidikan SLTP yaitu sebesar 8,6 persen. Hal ini dikarenakan Sardine Restaurant Seminyak Bali lebih mengutamakan karyawan dengan soft skill dan hard skill tinggi yang saat ini banyak dibutuhkan di berbagai bagian pada Sardine Restaurant Seminyak Bali hal tersebut cenderung lebih dimiliki oleh karyawan pendidikan Sarjana (S1). Berdasarkan lama bekerja menunjukkan bahwa sebagian besar responden sudah bekerja selama kurang lebih > 2 - 4 Tahun dengan persentase sebesar 46,5 persen, sedangkan responden dengan persentase terkecil sudah bekerja selama 1 Tahun yaitu sebesar 8,6 persen. Hal ini menunjukkan bahwa tingkat loyalitas karyawan di Sardine Restaurant Seminyak Bali cukup baik yang di sebabkan oleh berbagai faktor seperti kesejahteraan karyawan, rasa nyaman dan pekerjaan yang disenangi oleh karyawan.

\section{Hasil Uji Validitas}

Uji validitas bertujuan untuk mengukur pertanyaan-pertanyaan kuesioner yang harus dibuang atau diganti karena dianggap tidak relevan. Item instrumen dianggap valid jika lebih $\geq 0,3$. Berikut adalah hasil uji validitas dari penelitian ini. 
Tabel 2.

Uji Validitas

\begin{tabular}{lllll}
\hline No & Variabel & Indikator & Korelasi & Keterangan \\
\hline 1 & Employee retention $(\mathrm{Y})$ & $\mathrm{Y} 1$ & 0,872 & Valid \\
& & $\mathrm{Y} 2$ & 0,835 & Valid \\
& & $\mathrm{Y} 3$ & 0,860 & Valid \\
& & $\mathrm{Y} 4$ & 0,859 & Valid \\
& & $\mathrm{Y} 5$ & 0,684 & Valid \\
\hline 2 & \multirow{2}{*}{ Talent management $(\mathrm{X})$} & $\mathrm{X} 1.1$ & 0,854 & Valid \\
& & $\mathrm{X} 1.2$ & 0,740 & Valid \\
& & $\mathrm{X} 1.3$ & 0,859 & Valid \\
& & $\mathrm{X} 1.4$ & 0,583 & Valid \\
& & $\mathrm{X} 1.5$ & 0,660 & Valid \\
& & $\mathrm{X} 1.6$ & 0,720 & Valid \\
\hline 3 & Employee engagement $(\mathrm{M})$ & $\mathrm{M} 1.1$ & 0,689 & Valid \\
& & $\mathrm{M} 1.2$ & 0,749 & Valid \\
& & $\mathrm{M} 1.3$ & 0,872 & Valid \\
\hline
\end{tabular}

Sumber: Data primer diolah, 2017

Tabel 2 menjelaskan bahwa masih-masing indikator variabel memiliki nilai pearson correlation lebih besar dari 0,30 , Hal ini menunjukkan bahwa indikator yang dipakai layak digunakan untuk mengukur apa yang seharusnya diukur dan dapat mengungkap data dari variabel yang diteliti secara tepat.

\section{Hasil Uji Reliabilitas}

Uji reliabilitas mampu menunjukan sejauh mana instrument dapat dipercaya dan diharapkan. Nilai suatu instrument dikatakan reliable apabila nilai Alpha Cronbach $\geq 0,6$. Hasil uji reliabilitas dapat dilihat pada Tabel 3. berikut.

Tabel 3.

Hasil Uji Reliabilias

\begin{tabular}{clcc}
\hline No & \multicolumn{1}{c}{ Variabel } & $\begin{array}{c}\text { Cronbadh's } \\
\text { Alpha }\end{array}$ & Keterangan \\
\hline 1 & Employee retention $(\mathrm{Y})$ & 0,839 & Reliabel \\
2 & Talent management $(\mathrm{X})$ & 0,661 & Reliabel \\
3 & Employee engagement $(\mathrm{M})$ & 0,875 & Reliabel \\
\hline
\end{tabular}

Sumber: Data primer diolah, 2017

Tabel 3 di atas menjelaskan bahwa nilai Cronbach's Alpha untuk masingmasing variabel $>0,6$. Hal ini menunjukkan alat ukur tersebut akan memberikan 
hasil yang konsisten apabila alat ukur tesebut digunakan kembali untuk meneliti obyek yang sama.

\section{Hasil Analisis Jalur}

Berdasarkan hasil perhitungan koefisien regresi, nilai error dan determinasi total, maka dapat disusun diagram model analisis jalur seperti pada gambar 2 . sebagai berikut.

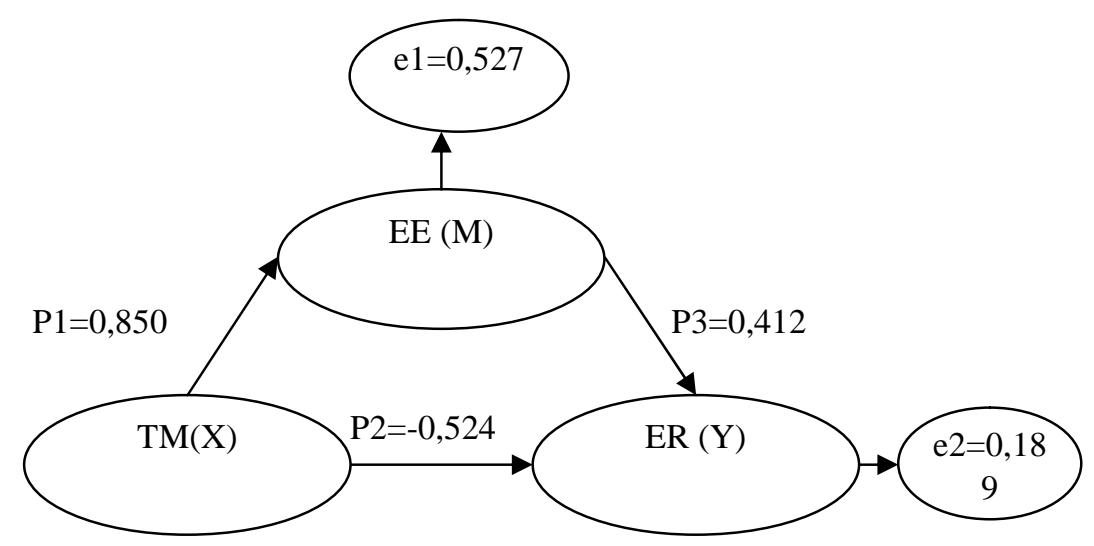

Gambar 2. Model Diagram Jalur Akhir

Gambar 2 menggambarkan koefisien jalur pada model pengaruh talent management terhadap employee retention melalui employee engagement. Hasil analisis pada Gambar 2 terlihat bahwa koefisien jalur pengaruh talent management terhadap employee retention setelah variabel employee engagement dilibatkan tidak bernilai 0, dengan demikian maka employee engagement memediasi secara parsial positif pengaruh talent management terhadap employee retention.

Berdasarkan hasil dari koefisien jalur pada hipotesis penelitian, maka dapat digambarkan hubungan kausal antar variabel talent management (X), 
employee engagement (M) terhadap employee retention (Y). Perhitungan pengaruh antar variabel dirangkum dalam Tabel 4.

Tabel 4.

Pengaruh Langsung dan Pengaruh Tidak Langsung serta Pengaruh Total Talent Management (X), Employee Engagement (M), dan Employee Retention (Y)

\begin{tabular}{llccc}
\hline & $\begin{array}{c}\text { Pengaruh } \\
\text { Variabel }\end{array}$ & $\begin{array}{c}\text { Pengaruh } \\
\text { Langsung }\end{array}$ & $\begin{array}{c}\text { Pengaruh Tidak Langsung M } \\
(\mathbf{p 1} \times \text { p3 }\end{array}$ & Pengaruh Total \\
\hline $\mathrm{P} 1$ & $\mathrm{X} \rightarrow \mathrm{M}$ & 0,429 & - & 0,429 \\
$\mathrm{P} 2$ & $\mathrm{X} \rightarrow \mathrm{Y}$ & 0,465 & - & 0,465 \\
$\mathrm{P} 3$ & $\mathrm{M} \rightarrow \mathrm{Y}$ & 0,725 & - & 0,725 \\
P4 & $\mathrm{X} \rightarrow \mathrm{M} \rightarrow \mathrm{Y}$ & 0,429 & 0,311 & 0,740 \\
\hline
\end{tabular}

Sumber: Data primer diolah, 2017

Nilai determinasi total sebesar 0,967 mempunyai arti bahwa sebesar 96,7\% variasi employee retention dipengaruhi oleh variasi talent management dan employee engagement, sedangkan sisanya sebesar 3,3 persen dijelaskan oleh faktor lain yang tidak dimasukkan ke dalam model.

\section{Uji Sobel}

Uji sobel digunakan untuk menguji signifikansi variabel employee engagement sebagai variabel mediasi terhadap pengaruh variabel talent management pada employee retention. Hasil kalkulasi uji sobel diperoleh nilai $\mathrm{Z}=$ $5,868>1,96$ tingkat signifikansi $0.000<0.05$ artinya variabel mediator employee engagement dinilai secara signifikan memediasi pengaruh talent management terhadap employee retention. 


\section{Pengaruh Talent Management Terhadap Employee Engagement}

Nilai Standardized Coefficients Beta sebesar 0,429 dan nilai sig t sebesar $0,000<0,05$ artinya $\mathrm{H}_{0}$ diterima. Hal ini berarti variabel Talent management berpengaruh positif dan signifikan secara parsial terhadap employee engagement. Hasil penelitian Nurul et al. (2014) mengindikasikan keterlibatan karyawan yang dimediasi memiliki hubungan antara praktek talent management (pegawai pengembangan karir dan penghargaan dan pengakuan) dan employee engagement.

Hasil penelitian Ali et al. (2014) menunjukkan bahwa, praktek talent management dijadikan bagian penting yang mempengaruhi employee engagement. Hasil penelitian Irmawaty \& Mailani (2016) menunjukkan bahwa, ada hubungan yang signifikan antara talent management dengan employee engagement. Mohamed (2014) membuktikan bahwa, talent management mempunyai korelasi positif dan berpengaruh signifikan terhadap employee engagement. Employee engagement yang efektif mendorong stimulasi lingkungan pada organisasi, seperti memberikan pengembangan dan pembelajaran, dukungan, penghargaan dan pengakuan dalam program manajemen bakat yang diterapkan perusahaan (Glen, 2006; Lockwood, 2007).

\section{Pengaruh Talent Management Terhadap Employee Retention}

Nilai Standardized Coefficients Beta sebesar 0,465 dan nilai sig t sebesar $0,000<0,05$, oleh karena Sig $\mathrm{t}=0,000 \leq 0,05$ maka $\mathrm{H}_{0}$ diterima. Hal Ini berarti variabel talent management berpengaruh positif dan signifikan terhadap employee retention. Langkah yang paling penting dari talent management adalah retensi karyawan berbakat dalam organisasi. Hal ini karena karyawan berbakat diyakini 
sebagai suatu investasi utama organisasi dan memberikan alasan mengapa perusahaan perlu mempertahankan mereka dalam organisasi.

Oladapo (2014) meneliti tentang pengaruh talent management terhadap retensi karyawan dan membuktikan bahwa retensi karyawan merupakan faktor utama dalam mengurangi jumlah turnover intention. Dalam penelitan tersebut disimpulkan bahwa ada pengaruh yang signifikan antara talent management dalam menarik, mempekerjakan dan mengembangkan karyawan serta mempertahankan karyawan. Kataike (2013) melakukan penelitian yang berusaha untuk mengetahui hubungan antara talent management dan retensi karyawan dan ditemukan adanya hubungan positif yang kuat antara talent management dan retensi staff, oleh karena itu manajemen harus lebih memperhatikan staff berbakat untuk mempertahankan layanan mereka dalam jangka panjang. Studi tersebut menyimpulkan bahwa manajemen talenta tidak dapat dipisahkan dari retensi karyawan karena mereka berjalan beriringan. Penelitian Ali et al. (2014) menemukan bahwa, terdapat hubungan positif dan signifikan antara talent management dengan employee retention. Phelister (2016) membuktikan bahwa, talent management mempunyai pengaruh signifikan terhadap employee retention.

\section{Pengaruh Employee Engagement Terhadap Employee Retention}

Hasil uji parsial menunjukan bahwa employee engagement berpengaruh positif dan signifikan terhadap employee retention. Hal ini berarti kedua variabel memiliki hubungan positif erat dan signifikan antara employee engagement dan talent management. Nurul et al. (2014) membuktikan bahwa, terdapat hubungan yang signifikan dan positif antara employee engagement dengan employee 
retention. Employee engagement memiliki pengaruh yang cukup besar terhadap kinerja organisasi, produktivitas karyawan, dan kemudahan rekrutmen dan retensi karyawan (Bhatnagar, 2007).

Lockwood (2007) menyatakan dalam sebuah survei global terhadap tingkat keterlibatan 50.000 karyawan di 27 negara, penelitian oleh Corporate Dewan Kepemimpinan menekankan hubungan employee engagement dengan kesuksesan bisnis dan kesuksesannya berdampak langsung terhadap kinerja dan retensi karyawan. Penelitian Yogendra (2015) membuktikan bahwa, employee engagement ditemukan memiliki signifikansi yang kuat dan hubungan positif terhadap employee retention. Penelitian Sorasak (2014) menemukan bahwa, employee engagement memiliki hubungan signifikan dan korelasi positif dengan employee retention. Hal yang sama dinyatakan oleh Oladapo (2014), terciptanya hubungan positif antara variabel employee engagement dengan employee retention.

Pengaruh Employee Engagement dalam Memediasi Talent Management terhadap Employee Engagement

Hasil uji mediasi menyatakan employee engagement mampu memberikan pengaruh positif dalam memediasi talent management terhadap employee retention. Hal ini berarti hubungan positif antara talent management dan employee retention mampu di mediasi oleh employee engagement. Penelitian Ali \& Hamid (2014) menyatakan bahwa, employee engagement sebagai variabel mediasi mampu menciptakan hubungan positif antara talent management dengan employee retention. Nurul et al. (2014) membuktikan bahwa, employee 
engagement merupakan variabel mediasi antara talent management dengan employee retention.

Bidayatul (2015) dalam penelitiannya membuktikan bahwa, employee engagement merupakan variabel yang memediasi hubungan antara talent management terhadap employee retention. Keterlibatan sebagai mediator dalam hubungan antara praktik manajemen talenta dan retensi karyawan membuatnya sangat berharga untuk memperluas bukti dalam penelitian ini. Dipertegas oleh penelitian Stefanus \& Echy (2014), employee engagement mampu memediasi pengaruh positif talent management terhadap employee retention. Theresha \& Tinjung (2015) membuktikan bahwa, employee engagement mampu memediasi variabel talent management dengan employee retention

\section{SIMPULAN DAN SARAN}

Berdasarkan pembahasan hasil penelitian di atas, dapat disimpulkan bahwa talent management memiliki pengaruh positif dan signifikan terhadap employee engagement dan employee retention, employee engagement memiliki pengaruh positif dan signifikan terhadap employee retention, employee engagement mampu memberikan pengaruh positif dalam memediasi hubungan talent management terhadap employee retention pada karyawan Sardine Restaurant Seminyak Bali. Sementara itu, saran yang dapat diberikan kepada pihak Sardine Restaurant Seminyak Bali sebaiknya perusahaan lebih efektif dan cermat dalam mengidentifikasikan orang-orang yang berbakat dan memberikan rewards kepada mereka, sehingga karyawan akan memiliki rasa loyalitas terhadap perusahaan. Selain itu, sebaiknya perusahaan memperbaiki dan menghilangkan beberapa 
aturan atau budaya perusahaan yang dirasa kurang mendukung karyawan dalam bekerja dengan yang baru, sehingga karyawan mampu bekerja dengan optimal dan perusahaan juga perlu memberikan kenyaman dan dukungan kepada karyawan dalam bekerja agar bersedia untuk bekerja keras atau ekstra keras demi organisasi. Perusahaan perlu memberikan apresiasi atas hasil kerja mereka dan menempatkan pada posisi yang sesuai.

\section{DAFTAR RUJUKAN}

Adab, Farisul dan Wahibur Rokhman. 2015. Pengaruh Etika Kerja Islam Terhadap Komitmen Organisasi, Retensi Karyawan dan Produktivitas. EQUILIBRIUM, Vol. 3, No. 1.

Albrecht, S.L, Ed. 2010. Handbook of Employee Engagement: Persepectives, Issues, Research and Practice. Glos, England: Edward Elgar.

Alias, Nurul Ezaili., Norzanah Mohd Noor., Roshidi Hassan. 2014. Examining the Mediating Effect of Employee Enagement on the Relationship between Talent Management Practices and Employee Retention in the Information and Technology (IT) Organizations in Malaysia. Journal of Human Resources Management and Labor Studies. 2(2): h: 227-242.

Aljunaibi, Mohamed Musallam. 2014. Talent Management and Employee Enagement. Dissertation Submitted in Partial Fulfillment of MSc in Project Management Faculty of Engineering \& IT Dissertation Supervisor Professor Abubakr Suliman. The British University in Dubai.

Astuti, Diah Puji dan Mutiara Sibarani Panggabean.2014.Pengaruh Kompensasi Terhadap Retensi Karyawan Melalui Kepuasan Kerja dan Komitmen Afektif Pada Beberapa Rumah Sakit di DKI Jakarta.Jurnal Manajemen dan Pemasaran Jasa.Vol7, No1.

Bhattacharya, Yogendra. 2015. Employee Engagement as a Predictor of Seafarer Retention: A Study among Indian Officers. The Asian Journal of Shipping and Logistics. Vol 31, Issue 2. Pages 295-318.

Bidisha, L. D and Mukulesh, B.2013.Employee Retention: A Review of Literature.Journal of Business and Management.14,8-6. 
Capelli, Peter and JR Keller.2014.Talent Management: Conceptual Approaches and Practical Challenges.Annual Review of Organizational Psychology and Organizational Behavior.Vol.1:305-331.

Davies, B and Davies, B.J., 2010.Talent Management in Academic. International Journal of Education Management.Vol 24,issue 5, Emeral Insight.

Dash, Bidya. 2013. Employee Engagement and HR Initiatives: A Conceptual Study, International Journal on Global Business Management \& Research. 1(2): h: 1-21.

Dhanalaksmi dan K Blanga Gurunathan. 2014. A Study on "Talent Management A Strategy to Influence Employee Engagement and its Affect on the Organizational Outcome. International Journal of Business and Administration Research Review. 2(4): h: 1-11.

Hasibuan, Malayu, S.P., 2007. Manajemen Sumber Daya Manusia. Jakarta : Cetakan 9. PT. Bumi Aksara.

Irmawaty \& Mailani Hamdani. 2016. Pengaruh Talent Management Terhadap Pengembangan Karir Pegawai di Universitas Terbuka. Jurnal Organisasi dan Manajemen. 12(2): h: 97-104.

Isfahani, Ali Chitsaz dan Hamid Reza Boustani. 2014. Effect of Talent Management on Employees Retention: The Mediate Effect of Organizational Trust. International Journal of Academic Research in Economics and Management Sciences. 3(5): h: 1-15.

Kamil, Bidayatul Akmal Mustafa. 2015. The Relationship of Talent Management and Succession Planning with Employee Retention in Higher Education in Instutions: Roles of Career Development and Employee Engagement as Mediatiors. A Thesis Submitted in Fulfillment of the Requirement for the Degree of Doctor of Philosophy in Business Administration. 2(4): h:1-21.

Mathis, Robert L dan John H Jackson, 2006. Manajemen Sumber Daya Manusia. Jakarta : Salemba Empat.

Mathis, R., Jackson, J. (2009). Human Resource Management. (12th ed.).Mason, $\mathrm{OH}$ : Thomson South-Western.

Nisa, Ridha Choirun., Endang Siti Astuti., Arik Prasetya.2016.Pengaruh Manajemen Talenta dan Manajemen Pengetahuan Terhadap Kinerja Karyawan.Jurnal Administrasi Bisnis (JAB), Vol.39, No.2.

Oladapo, Victor. 2014. The Impact of Talent Management on Retention. Journal of Business Studies Quarterly. 5(3): h: 2152-1034. 
Pimapunsri, Punee. 2013. Talent Management Practices : The Case of Companies in Thailand. GSTF International Journal on Media \& Communications $(J M C)$, Vol.1, No.1.

Sadana, Stefanus \& Echy Alsep Vany. 2014. Pengaruh Employee Engagement dan Workplace Well-being terhadap Turnover Intention (Studi pada Kantor Akuntan Publik ABC \& Rekan). Jurnal Organisasi dan Manajemen. 1(2): h: 1-24Santoso.

Schaufeli, W. B., Salanova, M., Gonza'lez-Roma', V., \& Bakker, A.(2002).The Measurement of Engagement and Burnout: A Two Sample Confirmatory Factor Analytic Approach. Journal of Happiness Studies, 3: 71-92.

Silvia, Kataike. 2013. Relationship Between Talent Management and Employee Retention in Commercial Banks of Kenya. Research Project Submitted in Partial Fulfilment of the Requirement for the Award of the Degree of Master of Business Administration (MBA), School of Business, University of Nairobi.

Sugiyono. 2013. Metode Penelitian Bisnis. Bandung: CV Alfabeta.

Suresh, Latha dan R. Krishnaraj.2015.A Study on the Importance of Employee Retention in Pharmaceutical Sector in India. International Journal of Pharmaceutical Sciences Review and Research, 32(1). Article No. 19, Pages: 108-111.

Susilo, Andri. 2014. Pengaruh Retensi Karyawan dan Kepuasan Pelanggan Terhadap Kinerja. Jurnal Studia Akuntansi dan Bisnis, Vol.1 No.3.

Then, Theresha \& Tinjung Desy Nursanti. 2015. Analisis Pengaruh Job Resources Terhadap Employee Engagement dan dampaknya pada Turnover Intention pada Bank DKI. Skripsi Bina Nusantara University.

Tiwari, U \& Shrivastava, D. 2013. Strategies and Practices of Talent Management and their Impact on Employee Retention and Effectiveness. The international Journal of Management. 2 (4): h: 11-29.

Wijayanti, Catur Wulan dan Harlina Nurtjanjanti.2015. Perceived Organizational Support dan Retensi Pada Karyawan PKWT Proyek Dermaga Petikemas PT. PP (Persero) Jakarta. Jurnal Empati.Volume 4(1) 49-54 